\title{
Liraglutide inhibits the proliferation and promotes the apoptosis of MCF-7 human breast cancer cells through downregulation of microRNA-27a expression
}

\author{
WEI ZHAO ${ }^{1}$, XIAOHUI ZHANG ${ }^{1,2}$, ZHICHAO ZHOU ${ }^{1}$, BEI SUN ${ }^{1}$, WENYUAN GU ${ }^{3}$, JIA LIU ${ }^{1}$ and HONG ZHANG ${ }^{1}$ \\ ${ }^{1}$ Key Laboratory of Hormones and Development (Ministry of Health), Tianjin Key Laboratory of Metabolic Diseases, \\ Tianjin Metabolic Diseases Hospital and Tianjin Institute of Endocrinology, Tianjin Medical University, Tianjin 300070; \\ ${ }^{2}$ Department of Nutrition, First Teaching Hospital of Tianjin University of Traditional Chinese Medicine, Tianjin 300381; \\ ${ }^{3}$ Emergency Department, The Second Affiliated Hospital of Tianjin University of Traditional Chinese Medicine, \\ Tianjin 300150, P.R. China
}

Received July 14, 2017; Accepted December 11, 2017

DOI: $10.3892 / \mathrm{mmr} .2018 .8475$

\begin{abstract}
The use of glucagon-like peptide-1 analogues, such as liraglutide, as hypoglycemic drugs has been widely employed in clinical practice. Liraglutide is reported to exert potential anti-breast cancer effects, however the specific mechanisms of this action remain unknown. In the present study, MCF-7 human breast cancer cells were cultured in vitro and treated with various concentrations of liraglutide. Cell Counting Kit-8, colony formation and flow cytometry assays were performed to determine the proliferation and apoptosis of cells following treatment. Furthermore, reverse transcription-quantitative polymerase chain reaction was employed to measure the expression level of microRNA (miRNA/miR)-27a. In addition, miR-27a mimics, inhibitors and negative controls were transfected into MCF-7 cells and the proliferation and apoptosis of cells following transfection was subsequently determined. Western blotting was performed to detect alterations in the protein expression of AMP-activated protein kinase catalytic subunit $\alpha 2$ (AMPK $\alpha 2$ ), proliferating cell nuclear antigen and cleaved-caspase-3 following treatments. The results demonstrated that, following treatment with liraglutide, the proliferation of MCF-7 cells was reduced and the apoptosis was increased, compared with the control group; this effect was increased with increasing concentrations of liraglutide. In addition, liraglutide treatment downregulated miR-27a expression in MCF-7 cells. While the
\end{abstract}

Correspondence to: Dr Hong Zhang, Key Laboratory of Hormones and Development (Ministry of Health), Tianjin Key Laboratory of Metabolic Diseases, Tianjin Metabolic Diseases Hospital and Tianjin Institute of Endocrinology, Tianjin Medical University, 66 Tongan Road, Heping, Tianjin 300070, P.R. China

E-mail: zh80008@163.com

Key words: type 2 diabetes, breast cancer, glucagon-like peptide-1, liraglutide, microRNA-27a overexpression of miR-27a promoted cell proliferation and inhibited apoptosis, knockdown of endogenous miR-27a inhibited cell proliferation and promoted apoptosis in MCF-7 cells. Furthermore, the expression of AMPK $\alpha 2$ protein in the group transfected with miR-27a mimics was decreased, while it was increased in MCF-7 cells transfected with miR-27a inhibitors. In conclusion, liraglutide may have a role in the inhibition of proliferation and promotion of apoptosis in MCF-7 cells. Concerning the mechanism of these effects, liraglutide may inhibit miR-27a expression, which subsequently increases the expression of AMPK $\alpha 2$ protein. The present study provides an experimental basis for the clinical treatment strategies of T2DM patients with breast cancer.

\section{Introduction}

Numerous studies have confirmed that there is a positive association between tumorigenesis and diabetes. The risk of malignancy in patients with diabetes is $\sim 2$ times higher compared with non-diabetic individuals $(1,2)$. The incidence of breast cancer has increased rapidly; according to GLOBOCAN 2008 statistics, there were $\sim 1.38$ million new cases of breast cancer annually and $\sim 30 \%$ of patients succumbed to tumor metastases (3). A US cohort study, after a 20-year follow up, reported that women with type 2 diabetes mellitus (T2DM) had a $17 \%$ increased risk of breast cancer compared with non-diabetic individuals (4). The choice of hypoglycemic therapy for patients with T2DM that develop tumors has an important influence on the development of the tumor. This is an important issue that has received increased interest in T2DM research.

Liraglutide, a glucagon-like peptide (GLP)-1 analogue, has been widely employed as a novel antidiabetic drug as it increases insulin secretion and improves glycemic control. Studies have demonstrated that GLP-1 exhibits various extra-pancreatic effects, including the promotion of glycogen synthesis and fat production in the liver, skeletal muscle and adipose tissue, and roles in the activation of the feeding center and cardiovascular protection (5-7). The association between GLP-1 and tumors 
remains unclear at present. Ligumsky et al (8) demonstrated that the selective GLP-1 receptor exists on the surface of MDA-MB-231 breast cancer cells, and a GLP-1 receptor agonist acted on the GLP-1 receptor to inhibit the proliferation and promote the apoptosis of MDA-MB-231 cells. However, it has also been reported that GLP-1 receptor agonists have the potential to increase the risk of pancreatic and thyroid cancer $(9,10)$.

MicroRNAs (miRNAs/miRs) exist widely in organisms and are involved in the regulation of numerous physiological and pathological processes. An increasing number of studies have demonstrated that miRNAs may be involved in tumor formation by regulating the expression of tumor-associated genes (11-13). In breast cancer, miRNAs that are closely associated with metastasis are termed 'metastamiRs' (14). These miRNAs regulate the metastasis of breast cancer by modulating the signaling pathways associated with epithelial-mesenchymal transition and tumor metastasis (15). miR-27a is highly expressed in breast cancer, gastric cancer, pancreatic cancer and colon cancer as an oncogenic miRNA $(16,17)$. It functions by regulating the apoptosis, cell cycle and differentiation of breast cancer cells $(18,19)$.

Our previous study demonstrated that metformin may activate AMP-activated protein kinase (AMPK) in MCF-7 cells and downregulate the expression of miR-27a. AMPK is a key molecule in the regulation of biological energy metabolism (20). AMPK activation strongly inhibits the proliferation of various types of tumor cells and is therefore a promising antitumor target. AMPK consists of two subunits, $\alpha 1$ and $\alpha 2$. In breast cancer tissues and adjacent tissues, the expression of the AMPK $\alpha 1$ subunit is abundant, while the expression of AMPK $\alpha 2$ in breast cancer tissues is significantly lower compared with in adjacent tissues (21). Furthermore, breast epithelial carcinoma exhibits a marked reduction in AMPK $\alpha 2$ expression (22).

The existing literature has reported that liraglutide activates AMPK in muscle, liver and islet $\beta$-cells, exerting various biological effects (23-25). However, to the best of the authors' knowledge, whether liraglutide downregulates the expression of miR-27a and activates AMPK $\alpha 2$ to affect the proliferation and apoptosis of breast cancer cells is not currently clear. Therefore, the present study selected MCF-7 human breast cancer cells and aimed to perform a preliminary investigation of the effects of liraglutide on the proliferation and apoptosis of MCF-7 cells, and investigate the potential underlying mechanism.

\section{Materials and methods}

Cell culture. MCF-7 cell lines were obtained from the Cell Bank of the Type Culture Collection of Chinese Academy of Sciences (Beijing, China). Cells were cultured in RPMI-1640 medium (Invitrogen; Thermo Fisher Scientific, Inc., Waltham, MA, USA) supplemented with $10 \%$ fetal bovine serum (FBS; Hyclone; GE Healthcare, Logan, UT, USA), 100 U/ml penicillin and $100 \mu \mathrm{g} / \mathrm{ml}$ streptomycin in humidified air at $37^{\circ} \mathrm{C}$ with $5 \% \mathrm{CO}_{2}$. The media was replaced every 1-2 days.

Cell transfection. Briefly, $20 \mathrm{nM}$ mimic (5'-UUCACAGUG GCUAAGUUCCGC-3') or inhibitor (5'-GCGGAACUUAGC
CACUGUGAA-3') of miR-27a (Shanghai GenePharma Co., Ltd., Shanghai, China) were transfected into 6-well plates at a cell density of $1 \times 10^{6}$ cells per well using the transfection reagent Lipofectamine 2000 (Invitrogen; Thermo Fisher Scientific, Inc., Waltham, MA, USA) to activate or inactivate miR-27a activity, respectively. Negative controls for mimics (5'-UUG UACUACACAAAAGUACUG-3') and inhibitors (5'-CAGUAC UUUUGUGUAGUACAA-3') were employed. A mock group, which consisted of cells treated with Lipofectamine 2000 only, was also included. At $6 \mathrm{~h}$ after transfection, the transfection solution was replaced with RPMI-1640 medium supplemented with $10 \% \mathrm{FBS}, 100 \mathrm{U} / \mathrm{ml}$ penicillin and $100 \mu \mathrm{g} / \mathrm{ml}$ streptomycin. For RNA extraction and protein isolation, cells were treated for $48 \mathrm{~h}$ and then harvested. miRNA transfection efficiencies were determined by reverse transcription-quantitative polymerase chain reaction (RT-qPCR).

Detection of cell proliferation by cell counting Kit (CCK)-8 assay. MCF-7 cells were seeded in 96-well plates at 1,000 cells per well in $100 \mu \mathrm{l}$ cell culture medium and incubated at $37^{\circ} \mathrm{C}$ for $24 \mathrm{~h}$. All cells were divided into the following groups: Blank wells containing medium only, untreated control cells and test cells treated with different concentrations of liraglutide $(10,100,1,000$ or $10,000 \mathrm{nM})$. Cells were either treated with $10,100,1,000$ and 10,000 nM liraglutide for $24 \mathrm{~h}$ or 1,000 $\mathrm{nM}$ liraglutide for 24,48 and $72 \mathrm{~h}$ in an $5 \% \mathrm{CO}_{2}$, humidified atmosphere at $37^{\circ} \mathrm{C}$. Each group was established three holes. Following treatment with liraglutide or transfection with miR-27a mimics/inhibitors, $10 \mu \mathrm{l} \mathrm{CCK-8} \mathrm{solution} \mathrm{(Dojindo}$ Molecular Technologies, Inc., Kumamoto, Japan) was added into each well and incubated for $2 \mathrm{~h}$ in an $5 \% \mathrm{CO}_{2}$, humidified atmosphere at $37^{\circ} \mathrm{C}$, and the absorbance was detected at $450 \mathrm{~nm}$. The CCK-8 assay was performed three times.

Colony formation assay. Cells were seeded into 6-well plates (500 cells/well) and incubated at $37^{\circ} \mathrm{C}$ in an environment with $5 \% \mathrm{CO}_{2}$ for 2 days. Subsequently, cells were treated with $1,000 \mathrm{nM}$ liraglutide for $48 \mathrm{~h}$. The medium was refreshed with medium containing $10 \%$ FBS once every three days, and the colony formation was observed after 14 days. The number of colonies of more than 50 cells was counted using the inverted fluorescent microscope (IX51-A12PH; Olympus Corporation, Tokyo, Japan). Image magnification, x10. To identify colonies, $0.1 \%$ crystal violet staining was used for $20 \mathrm{~min}$ at $37^{\circ} \mathrm{C}$ (Beyotime Institute of Biotechnology, Haimen, China) and representative photographs were captured. Each experiment was performed in triplicate.

Cell apoptosis detection by flow cytometry. Cells were digested with $0.25 \%$ trypsin for $2 \mathrm{~min}$ and a single-cell suspension was prepared. Cells were subsequently seeded into 12 -well plates $\left(5 \times 10^{4}\right.$ cells/well) and incubated at $37^{\circ} \mathrm{C}$ in an environment with $5 \% \mathrm{CO}_{2}$ overnight. Following treatment with 1,000 $\mathrm{nM}$ liraglutide $48 \mathrm{~h}$ or transfection with miR-27a mimic/inhibitor $24 \mathrm{~h}$, the medium was transferred to a centrifuge tube (containing apoptotic or necrotic cells). PBS was used to wash the adherent cells, followed by digestion with $0.25 \%$ trypsin to prepare a single-cell suspension. Subsequently, the suspension was transferred to a centrifuge tube and centrifuged at $800 \mathrm{x}$ g for $5 \mathrm{~min}$ at 
$4^{\circ} \mathrm{C}$. Subsequently, cell suspension $(100 \mu \mathrm{l})$ was transferred to a $1.5 \mathrm{ml}$ Eppendorf tube, and $5 \mu \mathrm{l}$ annexin $\mathrm{V}$ and $5 \mu \mathrm{l}$ propidium iodide was added, according to the protocol of FITC Annexin V Apoptosis Detection kit I (BD Biosciences, Franklin Lakes, NJ, USA). After $15 \mathrm{~min}$ incubation at room temperature in the dark, flow cytometry was performed to analyze the changes in cell apoptosis using FACS Aria I (BD Biosciences, Franklin Lakes, NJ, USA).

AMPK small interfering (si)RNA transfection. AMPK $\alpha 2$ siRNA (5'-GAGAAGCAGAAGCACGACGTT-3') and scrambled control (5'-UUCUCCGAACGUGUCACGUTT-3') were purchased from Cell Signaling Technology, Inc., (Danvers, MA, USA). Cells were incubated at $37^{\circ} \mathrm{C}$ and $5 \% \mathrm{CO}_{2}$ until they reached a confluency of $70 \%$. Subsequently, all transient transfections were performed with $100 \mathrm{nM}$ AMPK $\alpha 2$ siRNA or scrambled control using Lipofectamine 2000, according to the manufacturer's protocol. After $6 \mathrm{~h}$, the transfection mixtures were replaced with RPMI-1640 with 10\% FBS. Cells were harvested at $48 \mathrm{~h}$ post-transfection.

$R T$-qPCR. Following treatment with 0, 10, 100 and 1,000 nM liraglutide for $48 \mathrm{~h}$ or transfection with miR-27a mimics/inhibitors, total miRNA from MCF-7 cells was extracted with an PureLink ${ }^{\mathrm{TM}}$ miRNA Isolation kit (Invitrogen; Thermo Fisher Scientific, Inc.), according to the manufacturer's protocol. The expression of miR-27a was measured using a mirVana ${ }^{\mathrm{TM}}$ qRT-PCR miRNA Detection kit (Invitrogen; Thermo Fisher Scientific, Inc.). The stemloop-RT primer of miR-27a is 5'-GTCGTATCCAGTGCAGGGTCCGAGGTA TTCGCACTGGATACGACGTGGA-3'. The thermocycling parameters of reverse transcriptase are $25^{\circ} \mathrm{C}$ for $10 \mathrm{~min}, 42^{\circ} \mathrm{C}$ for $1 \mathrm{~h}$ and $85^{\circ} \mathrm{C}$ for $5 \mathrm{~min}$. U6 small nuclear RNA was used for the normalization of relative abundance of miR-27a. The primer of miR-27a is 5'-TTCACAGTGGCTAAGTTCCGC-3' and universal primer $\mathrm{R}$ is $5^{\prime}$-CCAGTGCAGGGTCCG AGGT-3'. The primer of U6 is 5'-GCTTCGGCAGCACAT ATACTAAAAT-3' and 5'-ACGCTTCACGAATTTGCG TGTC-3'. A total of $100 \mathrm{ng}$ cDNA product amplified in the reverse transcription step above was added to a $20 \mu \mathrm{l}$ reaction volume using the following amplification program: $95^{\circ} \mathrm{C}$ for 5 min, followed by 40 amplification cycles of denaturation at $95^{\circ} \mathrm{C}$ for $10 \mathrm{sec}$, annealing at $62^{\circ} \mathrm{C}$ for $20 \mathrm{sec}$, and elongation at $72^{\circ} \mathrm{C}$ for $10 \mathrm{sec}$. For AMPK $\alpha 2 \mathrm{mRNA}$ expression analysis, which was performed following treatment with 0 , 10,100 and 1,000 $\mathrm{nM}$ liraglutide for $48 \mathrm{~h}$, transfection with miR-27a mimics/inhibitors or transfection with or without miR-27a mimics followed by treatment with $1,000 \mathrm{nM}$ liraglutide for $48 \mathrm{~h}$. Total RNA was extracted using TRIzol ${ }^{\mathrm{TM}}$ LS Reagent (Invitrogen; Thermo Fisher Scientific, Inc.), and the reverse-transcription reactions were performed using a TransScript First-Strand cDNA Synthesis SuperMix (Transgene Bio, Inc., Peking, China). The thermocycling parameters of reverse transcriptase are $25^{\circ} \mathrm{C}$ for $10 \mathrm{~min}, 42^{\circ} \mathrm{C}$ for $1 \mathrm{~h}$ and $85^{\circ} \mathrm{C}$ for $5 \mathrm{~min}$. qPCR amplification was performed using SYBR Premix Ex Taq (Takara Biotechnology Co., Ltd., Dalian, China). A total of $100 \mathrm{ng}$ of the cDNA product amplified in the reverse transcription step above was added to a $20 \mu \mathrm{l}$ reaction volume using the following thermocycling parameters: $95^{\circ} \mathrm{C}$ for $5 \mathrm{~min}$, followed by 40 amplification cycles of denaturation at $95^{\circ} \mathrm{C}$ for $10 \mathrm{sec}$, annealing at $58^{\circ} \mathrm{C}$ for $20 \mathrm{sec}$, and elongation at $72^{\circ} \mathrm{C}$ for $10 \mathrm{sec}$. The primers of AMPK $\alpha 2$ are forwards, 5'-GCCAAGAAGCAAATGAGA ATG-3', and reverse, 5'-GACACAACGCAAACTCCTGA-3'. The primers of GAPDH are forwards, 5'-ACCACAGTCCAT GCCATCAC-3', and reverse, 5'-TCCACCACCCTGTTGCTG TA-3'. The expression levels of the target genes were normalized to GAPDH. Standard PCR samples were analyzed with a Bio-Rad iQ ${ }^{\mathrm{TM}} 5$ thermal cycler (Bio-Rad Laboratories, Inc., Hercules, CA, USA). Melting curves were generated for each RT-qPCR to verify the specific amplification products and primer dimers of each PCR reaction. All qPCR reactions were performed in triplicate. miR-27a and AMPK $\alpha 2$ expression levels were normalized using the comparative $\mathrm{Cq}$ method (26), and relative fold changes were calculated by the $2^{-\Delta \Delta \mathrm{Cq}}$ equation.

Western blot analysis. Following treatment with 0, 10, 100 and 1,000 $\mathrm{nM}$ liraglutide for $48 \mathrm{~h}$, transfection with miR-27a mimics/inhibitors, transfection with or without miR-27a mimics followed by treatment with 1,000 nM liraglutide for $48 \mathrm{~h}$, or transfection with AMPK $\alpha 2$ siRNA followed by treatment with 1,000 nM liraglutide for $48 \mathrm{~h}$, cells were lysed with Radioimmunoprecipitation assay Lysis and Extraction Buffer (Thermo Fisher Scientific, Inc.). The cytosolic extracts were prepared by centrifuging the lysates twice at $10,800 \mathrm{x} \mathrm{g}$ for $10 \mathrm{~min}$ at $4^{\circ} \mathrm{C}$. The protein concentration in each lysate was measured by a bicinchoninic acid assay. Equal amounts of protein $(10 \mu \mathrm{l}, 500 \mathrm{ng} / \mathrm{ml})$ were separated by $10 \%$ SDS-PAGE minigels. Following electrophoresis, proteins were transferred onto a nitrocellulose membrane and blocked with 5\% bovine serum albumin (Sigma-Aldrich; Merck $\mathrm{KGaA}$ ) in $0.1 \%$ TBS-Tween (TBST) at room temperature for $2 \mathrm{~h}$. Subsequently, the membranes were incubated with a rabbit anti-AMPK $\alpha 2$ monoclonal antibody $(1: 1,000$; cat. no. 2757; Cell Signaling Technology, Inc.), a rabbit anti-proliferating cell nuclear antigen (PCNA) polyclonal antibody (1:1,000; cat. no. 13110; Cell Signaling Technology, Inc.), a rabbit anti-cleaved-caspase-3 polyclonal antibody $(1: 1,000$; cat. no. 9664; Cell Signaling Technology, Inc.), or GAPDH antibody (1:2,000; cat. no. 10494-1-AP; Protein Tech Group, Inc., Chicago, USA) overnight at $4^{\circ} \mathrm{C}$. After thorough rinsing with TBST, membranes were incubated with the second antibody goat anti-rabbit immunoglobulin $\mathrm{G}(\mathrm{H}+\mathrm{L})$-horseradish peroxidase (1:10,000; LK2001; Sungene Biotech, Co., Ltd., Tianjin, China) for $1 \mathrm{~h}$. After rinsing, chemiluminescent detection was performed using a Pierce ${ }^{\mathrm{TM}}$ ECL Western Blotting Substrate (Invitrogen; Thermo Fisher Scientific, Inc.), followed by exposing and developing X-ray film. Western blotting results were analyzed using an Image Lab 4.0 software system (Bio-Rad Laboratories, Inc.). Western blotting was performed at least three times.

Statistical analysis. Each experiment included at least three replicates. Data are presented as the mean \pm standard deviation. A one-way analysis of variance was used followed by Tukey's or Dunnett's post-hoc test to analyze the differences between multiplegroups. Statistical analyses were performed using SPSS 21.0 software (IBM Corp., Armonk, NY, USA). $\mathrm{P}<0.05$ was considered to indicate a statistically significant 
difference. Graphs were produced using GraphPad Prism v5.0 software (GraphPad Software, Inc., La Jolla, CA, USA).

\section{Results}

Liraglutide inhibits the proliferation and promotes the apoptosis of MCF-7 breast cancer cells. In order to investigate the effect of liraglutide on the proliferation of MCF-7 human breast cancer cells, cells were treated with 10, 100, 1,000 and 10,000 $\mathrm{nM}$ liraglutide for $48 \mathrm{~h}$ and a CCK-8 assay was performed to detect the optical density at $450 \mathrm{~nm}$. Optical density was decreased in cells treated with liraglutide in a dose-dependent manner compared with the control group (Fig. 1A and B). The cell survival rate values were calculated and were $90.13,62.80,41.44$ and $11.05 \%$, respectively, in 10, 100, 1,000 and 10,000 nM treatment groups (Fig. 1B). These results indicated that liraglutide exhibited a marked inhibitory effect on the proliferation of MCF-7 cells in a dose-dependent manner. Further CCK-8 assays were performed to investigate whether liraglutide inhibits the proliferation of MCF-7 cells in a time-dependent manner. The results demonstrated that there was no significant difference in the proliferation between the control and liraglutide groups at $24 \mathrm{~h}$, but significant differences were observed between control and liraglutide groups at 48 and $72 \mathrm{~h}$ time-points (Fig. 1C). The calculated cell survival rates were $86.88,54.69$ and $43.41 \%$ for liraglutide-treated cells at 24,48 and $72 \mathrm{~h}$ (Fig. 1D). There was no significant difference between the control and liraglutide groups at $24 \mathrm{~h}$; however, compared with the control group, the cell survival rates following liraglutide treatment were significantly decreased at 48 and $72 \mathrm{~h}$ time-points (Fig. 1D). These results indicated that liraglutide exhibited a marked inhibitory effect on the proliferation of MCF-7 cells in a time-dependent manner.

The cell colony formation assay is another laboratory technique used to determine alterations in cell proliferation. Following treatment of cells with 1,000 nM liraglutide for $48 \mathrm{~h}$, colony formation assay results demonstrated that significantly fewer colonies were formed compared with the control group (69.37 vs. 100\% in liraglutide and control groups, respectively; $\mathrm{P}<0.05$; Fig. $1 \mathrm{E}$ and $\mathrm{F}$ ). These results further confirmed that liraglutide exhibits a marked inhibitory effect on the proliferation of MCF-7 cells.

The effects of liraglutide on the apoptosis of MCF-7 cells were assessed by flow cytometry. The results demonstrated that treatment with 1,000 $\mathrm{nM}$ liraglutide for $48 \mathrm{~h}$ led to an increase in the percentage of apoptotic cells, compared with the control group. The percentages of early apoptotic and late apoptotic cells in the liraglutide treatment group were $1.26 \pm 0.18$ and $6.06 \pm 0.32 \%$, respectively, and the early apoptosis and late apoptosis percentages in the control group were $0.81 \pm 0.13$ and $4.27 \pm 0.26 \%$, respectively. The difference in the percentage of late apoptotic cells between the control and liraglutide treatment groups was statistically significant $(\mathrm{P}<0.05$; Fig. $1 \mathrm{G}$ and $\mathrm{H})$, while the difference in the percentage of early apoptotic cells was not significant (Fig. 1G and H). These results demonstrated that liraglutide may promote the apoptosis of MCF-7 cells.

Liraglutide inhibits miR-27a expression and upregulates $A M P K \alpha 2$. The results of RT-qPCR analysis demonstrated that treatment with 100 and 1,000 nM liraglutide significantly inhibited the expression of miR-27a and significantly increased the mRNA expression of AMPK $\alpha 2$, compared with untreated control cells $(\mathrm{P}<0.05$; Fig. $2 \mathrm{~A}$ and $\mathrm{B})$. The expression levels of miR-27a were reduced by $15.5,44.5$ and $61.8 \%$, respectively, in the 10,100 and $1,000 \mathrm{nM}$ treatment groups, compared with the control group (Fig. 2A). Compared with the control group, the mRNA expression of AMPK $\alpha 2$ was increased by 1.61, 6.63 and 9.25 times in 10, 100 and $1,000 \mathrm{nM}$ treatment groups, respectively (Fig. 2B). In addition, liraglutide treatment (100 and 1,000 nM) significantly increased the expression of AMPK $\alpha 2$ at the protein level, compared with the control group, as determined by western blotting $(\mathrm{P}<0.05$; Fig. $2 \mathrm{C})$. The protein expression of $\mathrm{AMPK} \alpha 2$ was $1.5,4.0$ and 6.8 times higher in the 10,100 and $1,000 \mathrm{nM}$ treatment groups, respectively, compared with the control group (Fig. 2C). These results indicated that miR-27a may promote the proliferation, and inhibit the apoptosis, of MCF-7 human breast cancer cells, and liraglutide may mediate its effects by downregulating miR-27a expression. Therefore, miR-27a may be a potential target for the prevention and treatment of breast cancer. Subsequently, experiments were performed using miR-27a mimics/inhibitors to investigate whether liraglutide may inhibit the proliferation and promote the apoptosis of MCF-7 cells by targeting miR-27a and influencing expression of AMPK $\alpha 2$, which has previously been validated as a target gene of miR-27a (27).

The present study confirmed that miR-27a exhibits a regulatory effect on the expression of AMPK $\alpha 2$. miR-27a mimics and inhibitors were transfected into MCF-7 cells. RT-qPCR results confirmed that transfection with miR-27a mimics was successful (Fig. 2D), and the results also demonstrated that overexpression of miR-27a led to downregulation of AMPK $\alpha 2$ mRNA expression by $57.77 \%$, compared with the NC group $(\mathrm{P}<0.05$; Fig. 2E). In addition, following transfection with miR-27a mimics, AMPK $\alpha 2$ protein expression was also downregulated by $52.55 \%$, compared with the NC group $(\mathrm{P}<0.05$; Fig. 2F). Successful transfection of miR-27a inhibitors was confirmed by RT-qPCR (Fig. 2G). Furthermore, following transfection with miR-27a inhibitors, AMPK $\alpha 2$ mRNA expression was increased 2.61 times $(\mathrm{P}<0.05$; Fig. $2 \mathrm{H})$ and AMPK $\alpha 2$ protein expression was increased 2.27 times $(\mathrm{P}<0.05$; Fig. 2I) compared with the NC group. These results indicated that miR-27a may negatively regulate AMPK $\alpha 2$.

miR-27a promotes the proliferation of MCF-7 human breast cancer cells and inhibits apoptosis. It was previously reported that miR-27a, as a carcinogenic miRNA, regulates key target genes to control the cell cycle check point to affect the growth of breast cancer cells (16). In order to investigate the role of miR-27a in the proliferation and apoptosis of MCF-7 cells, MCF-7 cells were transfected with miR-27a mimics and inhibitors. Following transfection with miR-27a mimics, the proliferation and cell survival rate was increased significantly compared with the negative control group $(\mathrm{P}<0.05$; Fig. 3A and B). Furthermore, flow cytometry demonstrated that, compared with the negative control group, the percentage of late apoptotic cells was significantly reduced in the cells transfected with miR-27a mimics $(2.16 \pm 0.41$ vs. $5.71 \pm 0.23 \%$ in miR-27a mimics and negative control groups, respectively; 
A

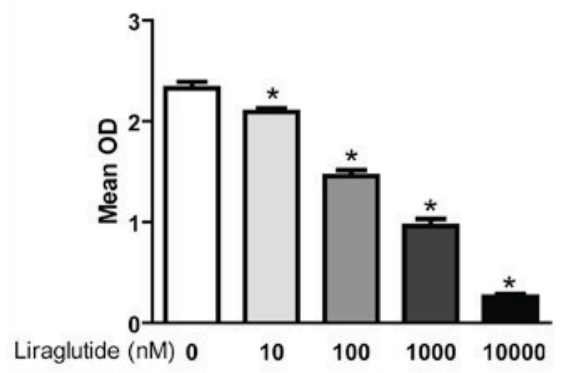

C

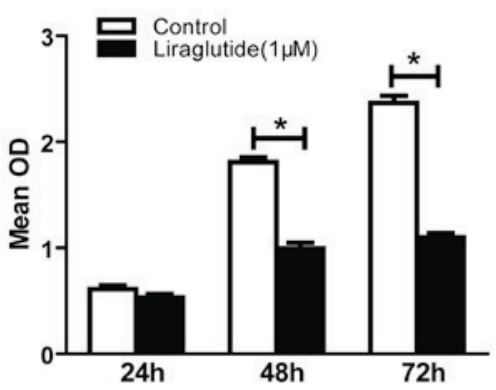

E

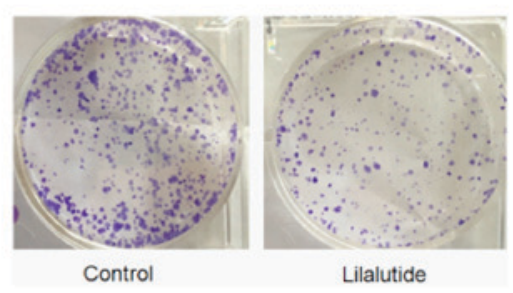

G

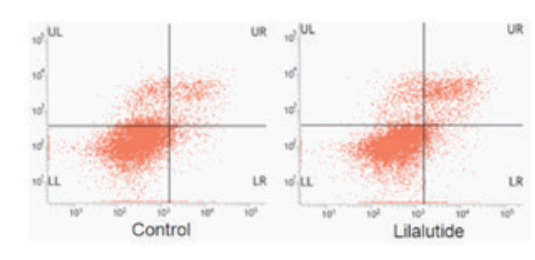

B

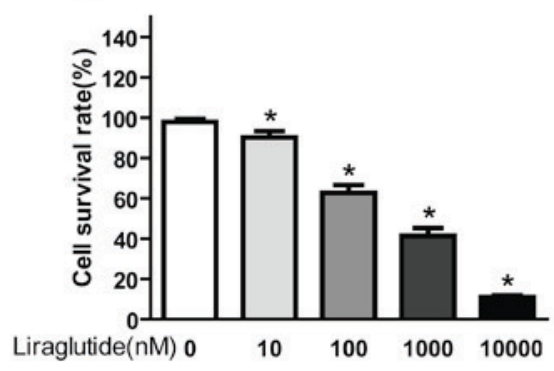

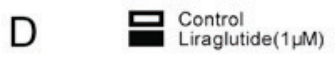

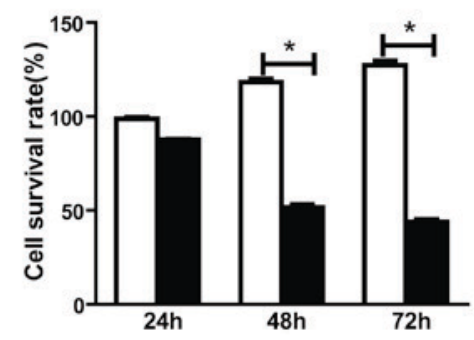

$\mathrm{F}$

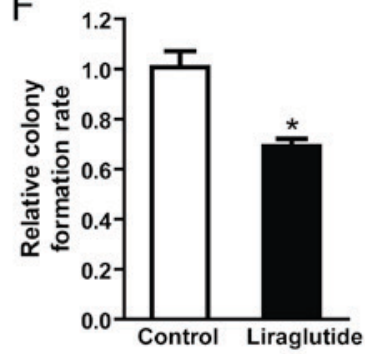

$\mathrm{H}$

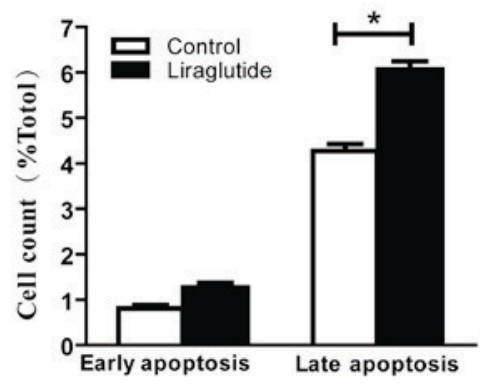

Figure 1. Liraglutide inhibits the proliferation and promotes apoptosis in the MCF-7 breast cancer cell line. (A) CCK-8 assay results demonstrated that with increasing liraglutide concentration, the mean OD values were reduced. (B) Cell survival rates in each group were calculated following CCK-8 assays (C) When 1,000 $\mathrm{nM}$ liraglutide was employed for 48 and $72 \mathrm{~h}$, cell proliferation was markedly inhibited. (D) Cell survival rates in each group were calculated following CCK-8 assays. (E) Representative images of cell colony formation assays. (F) Quantification of cell colony formation assay results confirmed that the colony formation capacity decreased significantly following treatment with $1,000 \mathrm{nM}$ liraglutide. (G) Representative flow cytometry plots in control cells or cells treated with 1,000 $\mathrm{nM}$ liraglutide. LR quadrant represents early apoptotic cells, and UR quadrant represents late apoptotic cells. (H) Quantified flow cytometry results demonstrated that the percentage of late apoptotic cells in the liraglutide treatment group increased significantly compared with the control group. Data are presented as the mean \pm standard deviation. For parts A and $\mathrm{B},{ }^{*} \mathrm{P}<0.05 \mathrm{vs} .0 \mathrm{nM}$ liraglutide group; for parts $\mathrm{C}, \mathrm{D}, \mathrm{F}$ and $\mathrm{H},{ }^{*} \mathrm{P}<0.05$, as indicated by brackets. CCK-8, Cell Counting Kit-8; OD, optical density.

$\mathrm{P}<0.05$; Fig. 3C and D). Correspondingly, in cells transfected with miR-27a inhibitor, the proliferation and cell survival were significantly lower compared with the negative control group $(\mathrm{P}<0.05$; Fig. $3 \mathrm{E}$ and $\mathrm{F})$, and the late apoptosis percentage was increased significantly compared with the negative control group (6.91 \pm 0.27 vs. $4.71 \pm 0.23 \%$ in miR-27a inhibitor and negative control groups, respectively; $\mathrm{P}<0.05$; Fig. $3 \mathrm{G}$ and $\mathrm{H}$ ). There was no statistical difference between the NC group and the mock group. These results indicated that miR-27a promoted the proliferation and inhibited the apoptosis of MCF-7 cells.

PCNA is only expressed in normal proliferating cells and tumor cells. It has an important role in the initiation of cell proliferation and is a good indicator of the cell proliferation. In a pre-test, no significant differences were observed between negative control mimics and negative control inhibitor groups and the mock group (data not shown). Therefore, although 
A

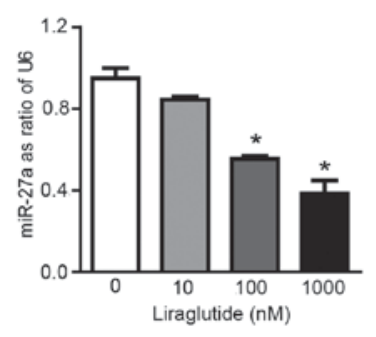

$\mathrm{D}$
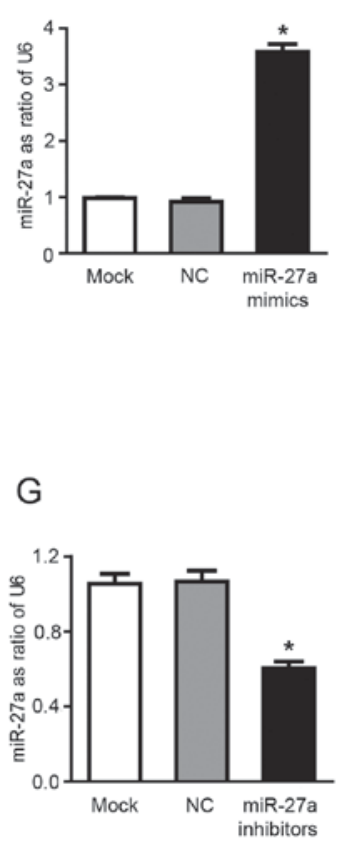

B

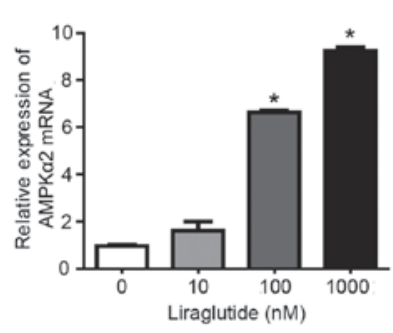

$E$

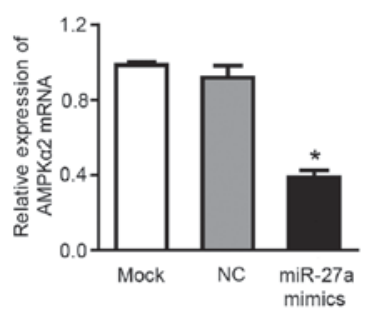

$\mathrm{H}$

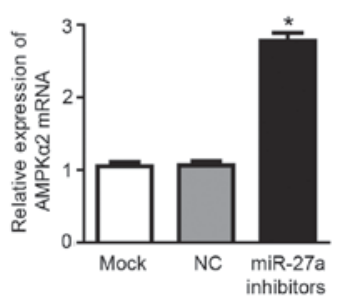

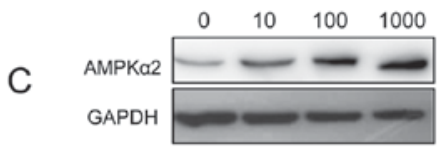

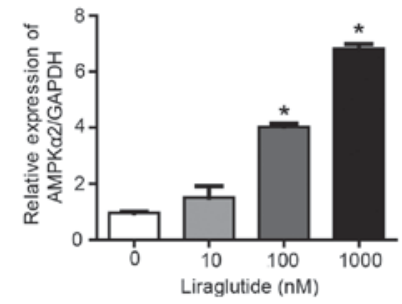

F
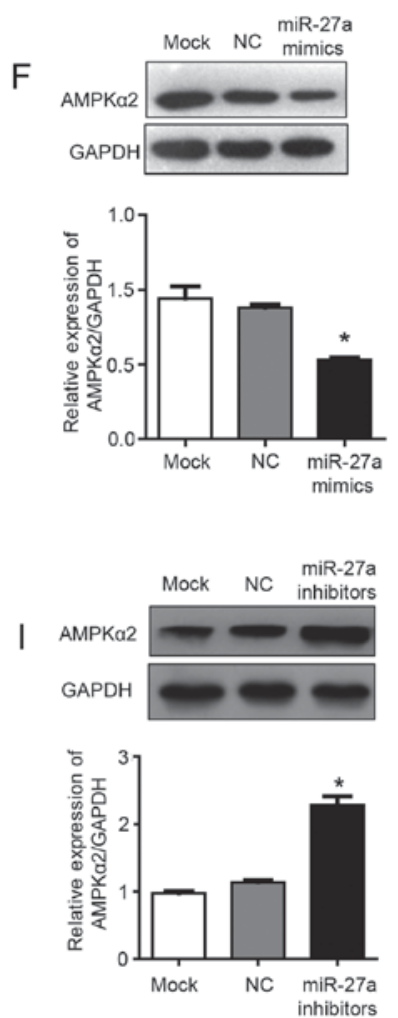

Figure 2. Liraglutide inhibits miR-27a expression and subsequently upregulates AMPK $\alpha 2$. Following treatment with 10, 100 and 1,000 nM liraglutide for $48 \mathrm{~h}$, RT-qPCR was performed to determine the mRNA levels of (A) miR-27a and (B) AMPK $\alpha 2$. (C) Western blotting was performed to measure the protein levels of AMPK 2 2. (D) RT-qPCR confirmed that transfection with miR-27a mimics led to the successful overexpression of miR-27a in MCF-7 cells. (E) RT-qPCR demonstrated that the mRNA levels of AMPK $\alpha 2$ were downregulated following transfection with miR-27a mimics. (F) Western blotting demonstrated that AMPKa2 protein expression was downregulated following transfection with miR-27a mimics. (G) RT-qPCR confirmed that transfection with miR-27a inhibitors led to the successful reduction of miR-27 levels in MCF-7 cells. (H) RT-qPCR demonstrated that AMPK 22 mRNA expression was increased following transfection with miR-27a inhibitors. (I) Western blotting demonstrated that AMPK 22 protein expression was increased following transfection with miR-27a inhibitors. Data are presented as the mean \pm standard deviation. For parts A-C, ${ }^{*} \mathrm{P}<0.05$ vs. 0 nM liraglutide; for parts $\mathrm{D}-\mathrm{I}$, ${ }^{*} \mathrm{P}<0.05$ vs. NC group. miR, microRNA; AMPK $\alpha 2$, AMP-activated protein kinase catalytic subunit $\alpha 2$; RT-qPCR, reverse transcription-quantitative polymerase chain reaction; NC, negative control; U6, U6 small nuclear RNA.

separate mimics and inhibitor negative controls were used for all aforementioned transfection results, negative control mimics were selected as a common control for the western blotting results presented in Fig. 3I and J. Previous studies have also included the use of a common control for mimics and inhibitor experiments $(28,29)$.

Western blotting demonstrated that the expression of PCNA was increased in cells transfected with miR-27a mimics, and was increased by $\sim 2$ times compared with the NC group $(\mathrm{P}<0.05$; Fig. 3I). Furthermore, PCNA expression was reduced in the group transfected with miR-27a inhibitors, with an expression of $\sim 43.22 \%$ of the NC group
$(\mathrm{P}<0.05$; Fig. 3I). These results further demonstrated that miR-27a may inhibit the proliferation of MCF-7 human breast cancer cells.

Caspase-3 is a key apoptotic factor in the caspase family. Western blotting demonstrated that the expression of cleaved-caspase-3 was decreased in cells transfected with miR-27a mimics, with an expression of $28.56 \%$ of the NC group $(\mathrm{P}<0.05$; Fig. 3J). Correspondingly, following transfection with miR-27a inhibitor, the cleaved-caspase-3 expression was 2.1 times higher compared with the NC group $(\mathrm{P}<0.05$; Fig. 3J). These results further indicated that miR-27a may promote the apoptosis of MCF-7 cells. 
A

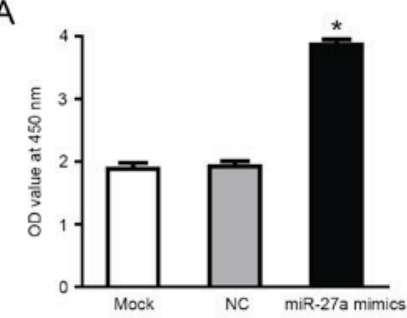

C

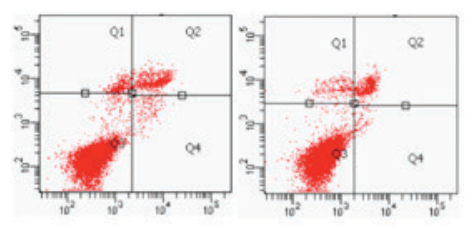

E

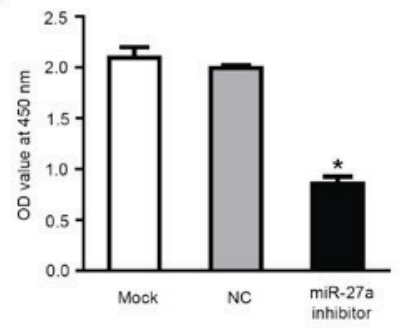

G

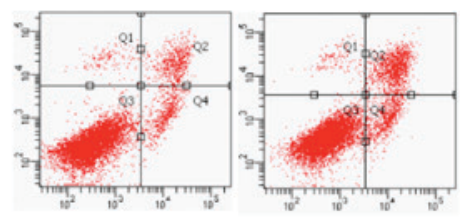

।
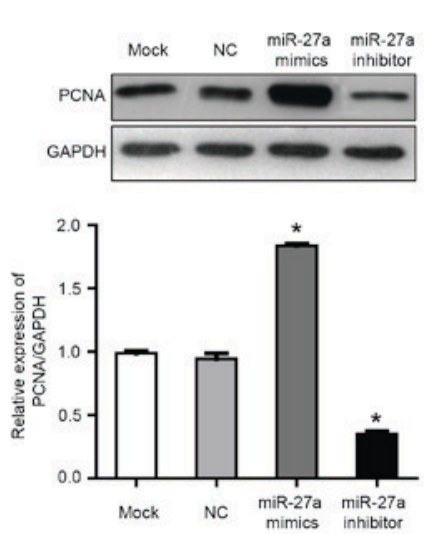

B

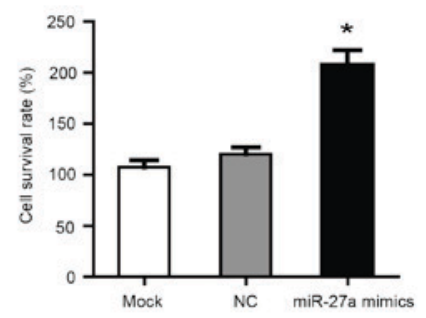

D

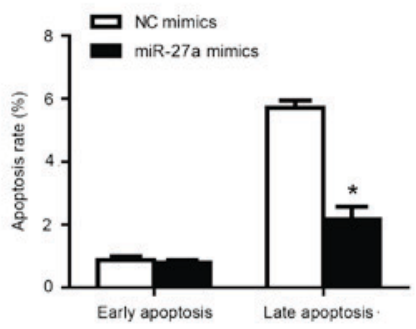

$\mathrm{F}$

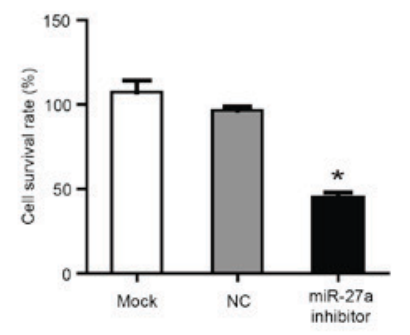

$\mathrm{H}$

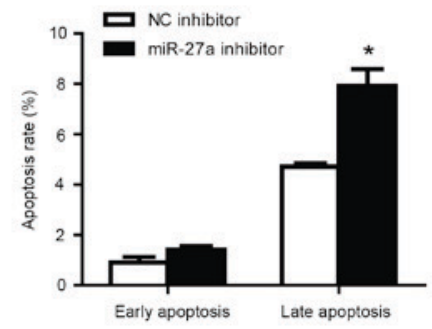

J
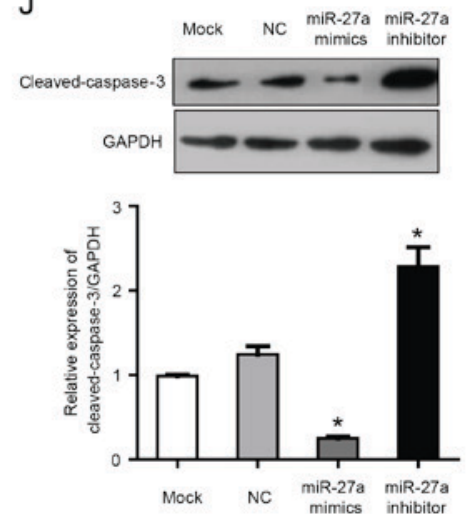

Figure 3. miR-27a overexpression promotes the proliferation and inhibits the apoptosis of MCF-7 human breast cancer cells. (A) CCK-8 assays demonstrated that cells transfected with miR-27a mimics exhibited enhanced proliferation. (B) Cell survival rates were calculated following CCK-8 assays. (C) Representative flow cytometry plots following transfection of MCF-7 cells with NC mimics or miR-27a mimics. The UR quadrant was considered to indicate late apoptotic cells and the LR quadrant was considered to indicate early apoptotic cells (D) Quantified flow cytometry results demonstrated that the percentage of late apoptotic cells was significantly reduced following transfection of cells with miR-27a mimics. (E) CCK-8 assays demonstrated that cells transfected with miR-27a inhibitors exhibited reduced proliferation. (F) Cell survival rates were calculated following CCK-8 assays. (G) Representative flow cytometry plots following transfection of MCF-7 cells with NC inhibitors or miR-27a inhibitors. The UR quadrant was considered to indicate late apoptotic cells and the LR quadrant was considered to indicate early apoptotic cells. (H) Quantified flow cytometry results demonstrated that the percentage of late apoptotic cells was significantly increased following transfection of cells with miR-27a inhibitors. (I) Western blotting demonstrated that transfection with miR-27a mimics led to a significant increase in the protein expression of PCNA, while miR-27a inhibitors significantly reduced PCNA protein expression. (J) Western blotting demonstrated that transfection with miR-27a mimics significantly reduced cleaved-caspase-3 expression, while miR-27a inhibitors significantly increased cleaved-caspase-3 protein levels. Data are presented as the mean \pm standard deviation. " $\mathrm{P}<0.05$ vs. NC group. miR, microRNA; CCK- 8 , Cell Counting Kit-8; $\mathrm{NC}$, negative control; PCNA, proliferating cell nuclear antigen; OD, optical density; UR, upper right; LR, lower right. 
Upregulation of $\mathrm{miR}-27$ a reverses the activation effects of liraglutide on $A M P K \alpha 2$. The previously discussed results indicated that the promotion of apoptosis by liraglutide may be associated with the activation of the AMPK $\alpha 2$ pathway, and miR-27a negatively regulates AMPK $\alpha 2$. Therefore, we hypothesized that the effect of liraglutide on apoptosis may be mediated via reduced miR-27a expression and activation of the AMPK $\alpha 2$ pathway.

The present study further investigated the effect of liraglutide in MCF-7 cells following transfection with miR-27a mimics. The results demonstrated that $\mathrm{AMPK} \alpha 2$ expression was increased by liraglutide in MCF-7 cells, compared with the control group, while its expression in the liraglutide + miR-27a mimics group was decreased compared with the liraglutide + negative control mimics group (Fig. 4A and B). These results indicated that the overexpression of miR-27a potentially impaired the effect of liraglutide on apoptosis in MCF-7 cells.

AMPKa2 knockdown reduces the inhibitory effect of liraglutide on MCF-7 cells. To determine whether AMPK is responsible for the inhibition of proliferation induced by liraglutide, MCF-7 cells were transfected with AMPK $\alpha 2$ siRNA. As demonstrated in Fig. 4C, cells exhibited a marked decrease in AMPKa2 protein expression, compared with the control siRNA group. With or without liraglutide treatment, knockdown of AMPK $\alpha 2$ increased the protein expression of PCNA, compared with cells transfected with control siRNA, indicating that proliferation was increased following AMPK $\alpha 2$ knockdown (Fig. 4D). These results indicate that AMPK activation may be essential for the inhibitory effect of liraglutide on the proliferation of MCF-7 cells. These results demonstrated that liraglutide-induced inhibition of proliferation may be associated with the AMPK pathway. Taken together, the results of the current study indicate that liraglutide, potentially through the miR-27a/AMPK $\alpha 2$ pathway, may promote apoptosis in MCF-7 cells (Fig. 4E).

\section{Discussion}

Breast cancer is among the most common types of malignant tumors that affect women, according to statistics from developed countries in North America and Europe (30). Several studies have reported that breast cancer incidence and mortality risk are closely associated with metabolic disease (31-33). The present study reported that liraglutide, which is widely employed for hypoglycemic treatment, also exhibited an inhibitory effect on the proliferation of MCF-7 cells and promoted apoptosis. These effects may be associated with the inhibition of miR-27a expression by liraglutide, and miR-27a negatively regulates AMPK $\alpha 2$ expression.

GLP-1 exerts its function primarily through binding to its receptor. GLP-1 receptors are not exclusive to the pancreas, and are also present in the gastrointestinal tract, brain, heart, aorta, kidney, lung, peripheral nervous system and other tissues and organs (34). In addition to a role in regulating blood glucose, GLP-1 also exhibits numerous extra-hypoglycemic effects. Liraglutide, a GLP-1 analogue, has 97\% homology with GLP-1 in the human body and regulates blood glucose through various mechanisms. It has been reported that sustained GLP-1 receptor activation may increase the incidence of colorectal cancer in patients with T2DM that exhibit hyperinsulinemia (35). However, a meta-analysis demonstrated that the use of liraglutide did not increase the incidence of acute pancreatitis and pancreatic cancer in patients with T2DM (36). Ligumsky et al (8) reported that exenatide, a GLP-1 receptor agonist, led to sustained activation of the GLP-1 receptor, which subsequently led to the inhibition of proliferation and promotion of apoptosis in MDA-MB-231 cells through the cyclic AMP pathway.

MCF-7 is the most commonly employed breast cancer cell line in research, and is estrogen receptor positive with a high proliferation rate. The results of the current study demonstrated that liraglutide effectively inhibited the proliferation of MCF-7 cells in a concentration- and time-dependent manner. Furthermore, colony formation assay and flow cytometry results also confirmed that liraglutide inhibited the proliferation of MCF-7 cells and promoted cell apoptosis.

AMPK is an important kinase that regulates energy homeostasis and also a key protein involved in various cellular signaling pathways, including those involved in the regulation of the cell cycle and apoptosis. A recent study reported that liraglutide activated AMPK in the muscle cells of mice, thereby regulating muscle cell translocation of glucose transporter 4 (37). Furthermore, Miao et al (24) demonstrated that liraglutide promoted the proliferation of insulin-producing $\beta$ cells through the AMPK/mechanistic target of rapamycin kinase (mTOR) signaling pathway, while Ben-Shlomo et al (38) reported that liraglutide inhibited the formation of fatty liver via the AMPK pathway. The present study also indicated that liraglutide activates AMPK. Therefore, liraglutide-induced inhibition of proliferation and apoptosis promotion in MCF-7 cells may be associated with the activation of AMPK.

miRNAs exhibit their biological roles through specific recognition of the 3'untranslated regions within target genes and through complementary base-pairing to inhibit target gene expression. miR-27, which includes miR-27a and miR-27b, has important biological functions. As an oncogenic miRNA, it has been reported to be highly expressed in breast, gastric, pancreatic and colon cancer. It has been reported that miR-27a regulates cell growth and differentiation, and is implicated in drug resistance, dose-dependently. Furthermore, miR-27a may promote the metastasis of cancer cells through induction of epithelial-mesenchymal transition. miR-27a was also reported to be involved in cell apoptosis, cell cycle checkpoints and metabolism (39). The results of the present study also confirmed that miR-27a exhibited an important role in inhibiting proliferation and promoting apoptosis in MCF-7 cells. Therefore, miR-27a may be employed as an effective target for the prevention and treatment of breast cancer. However, miR-27a inhibitor is not yet suitable for clinical application. The present study employed liraglutide, which is widely used in the clinic, to interfere with MCF-7 human breast cancer cells, and the results demonstrated that liraglutide inhibited miR-27a expression, which may provide a novel treatment option for the prevention and control of breast cancer by targeting miR-27a.

Our previous study verified that AMPK $\alpha 2$ was a target gene of miR-27a. AMPK $\alpha 2$ is one of the catalytic subunits of AMPK and its expression in MCF-7 human breast cancer cells is suppressed, as it functions as a tumor suppressor (27). Fox et al (21) investigated AMPK $\alpha 2$ expression among tumor 
A

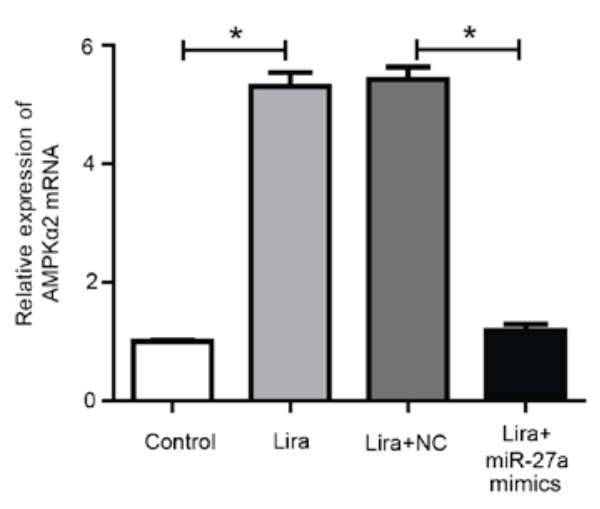

C
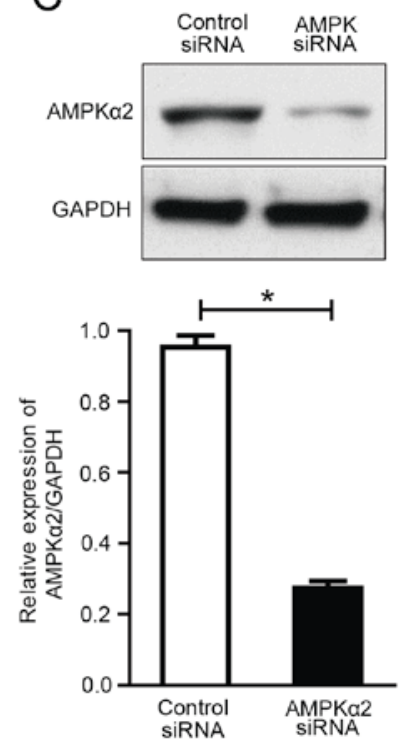

B
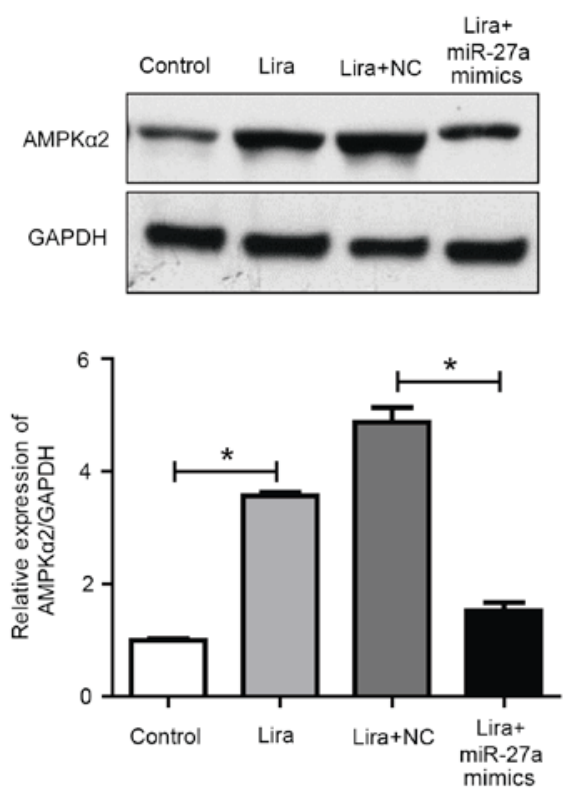

$\mathrm{D}$
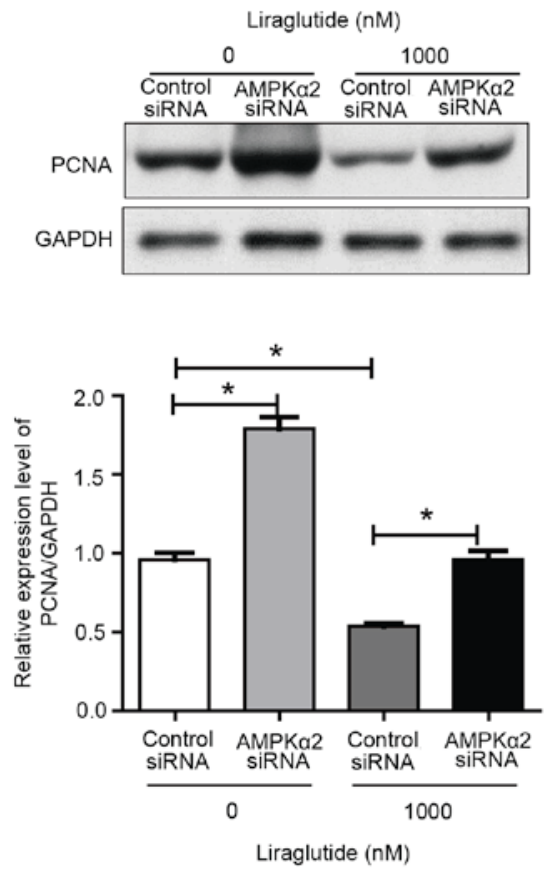

E

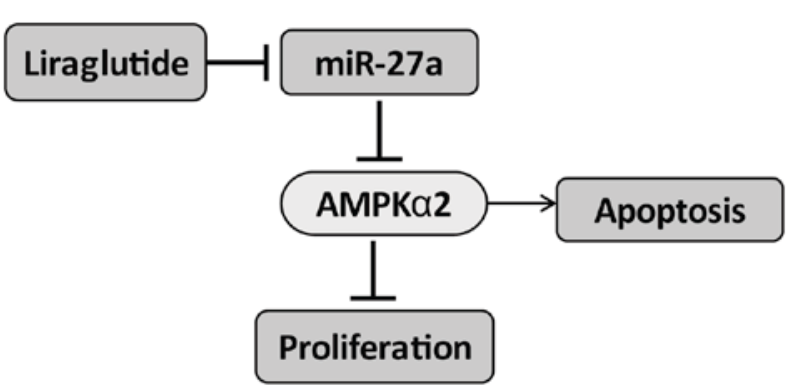

Figure 4. Upregulation of miR-27a reverses the liraglutide-induced activation of AMPK $\alpha 2$ and AMPK $\alpha 2$ siRNA inhibits liraglutide-induced inhibition of proliferation in MCF-7 cells. (A) AMPK $\alpha 2$ mRNA levels were measured by reverse transcription-quantitative polymerase chain reaction in MCF-7 cells transfected with or without miR-27a mimics and subsequently treated with liraglutide for $48 \mathrm{~h}$. (B) AMPK $\alpha 2$ protein levels were measured by western blotting in MCF-7 cells transfected with or without miR-27a mimics and subsequently treated with liraglutide for $48 \mathrm{~h}$. (C) MCF-7 cells were transfected with control siRNA or AMPK $\alpha 2$ siRNA for $48 \mathrm{~h}$ and western blotting was performed to measure AMPK $\alpha 2$ levels and confirm successful transfection. (D) MCF-7 cells were transfected with AMPK $\alpha 2$ siRNA and cultured with or without 1,000 nM liraglutide for $48 \mathrm{~h}$. The expression of PCNA was determined by western blot analysis. GAPDH served as the loading control. (E) Summary diagram of the regulatory pathway in the present study. In breast cancer cells, liraglutide inhibits miR-27a expression and subsequently activates the AMPK pathway, thereby leading to the induction of cell apoptosis. Data are presented as the mean \pm standard deviation. "P<0.05, as indicated by brackets. miR, microRNA; AMPK $\alpha 2$, AMP-activated protein kinase catalytic subunit $\alpha 2$; siRNA, small interfering RNA; PCNA, proliferating cell nuclear antigen; NC, negative control; Lira, liraglutide. 
samples, non-tumorous adjacent (ADJ) breast epithelial tissue and normal epithelial tissue samples, and the results demonstrated that AMPKa2 protein expression was reduced by $27 \%$ in tumor samples compared with the patient-matched ADJ samples and by $37 \%$ compared with normal epithelial tissue samples. Further experiments indicated that AMPK $\alpha 2$ arrested the cell cycle through cyclin D1 and reduced protein biosynthesis through the mTOR pathway. Furthermore, the same study reported that AMPK $\alpha 2$ may act directly on P53 resulting in MCF-7 cell apoptosis. The results of the present study demonstrated that liraglutide inhibited the proliferation and promoted the apoptosis of MCF-7 cells, which may occur via inhibition of miR-27a expression and subsequent upregulation of the miR-27a target gene, AMPK $\alpha 2$.

In conclusion, the present study demonstrated that the hypoglycemic drug liraglutide inhibited the proliferation and promoted the apoptosis of MCF-7 cells, exhibiting potential anti-breast cancer effects. In addition, the results demonstrated that liraglutide may function as an miR-27a inhibitor, thereby potentially providing a novel method for the clinical prevention and treatment of breast cancer. It has been previously reported that certain antidiabetic drugs, including insulin and sulfonylureas antidiabetic drugs, may affect the levels of insulin, inflammatory factors and insulin-like growth factor-1, thus increasing tumor risk in patients with T2DM $(40,41)$. The current study may provide a basis for the selection of hypoglycemic agents in patients with T2DM, particularly in patients with breast cancer. However, various issues are associated with the present study. For example, the results demonstrated that $100 \mathrm{nM}$ liraglutide inhibited miR-27a expression in MCF-7 cells, while $10 \mathrm{nM}$ liraglutide did not lead to a statistically significant decline. In addition, further investigation is required to determine whether $100 \mathrm{nM}$ liraglutide may lead to any side effects prior to clinical application. In conclusion, the current study may provide a novel direction for investigating the roles of GLP-1 besides its glucose-lowering effects.

\section{Acknowledgements}

This work was supported by the National Natural Science Foundation of China (grant no. 81400784) and the Natural Science Foundation of Tianjin (grant no. 16JCYBJC26800).

\section{References}

1. Noto H, Osame K, Sasazuki T and Noda M: Substantially increased risk of cancer in patients with diabetes mellitus: A systematic review and meta-analysis of epidemiologic evidence in Japan. J Diabetes Complications 24: 345-353, 2010.

2. Buysschaert M and Sadikot S: Diabetes and cancer: A 2013 synopsis. Diabetes Metab Syndr 7: 247-250, 2013.

3. Ferlay J, Shin HR, Bray F, Forman D, Mathers C and Parkin DM: Estimates of worldwide burden of cancer in 2008: GLOBOCAN 2008. Int J Cancer 127: 2893-2917, 2010.

4. Michels KB, Solomon CG, Hu FB, Rosner BA, Hankinson SE, Colditz GA and Manson JE; Nurses' Health Study: Type 2 diabetes and subsequent incidence of breast cancer in the Nurses Health Study. Diabetes Care 26: 1752-1758, 2003.

5. Dardevet D, Moore MC, Neal D, DiCostanzo CA, Snead W and Cherrington AD: Insulin-independent effects of GLP-1 on canine liver glucose metabolism: Duration of infusion and involvement of hepatoportal region. Am J Physiol Endocrinol Metab 287: E75-E81, 2004.
6. Sancho V, Trigo MV, González N, Valverde I, Malaisse WJ and Villanueva-Peñacarrillo ML: Effects of glucagon-like peptide-1 and exendins on kinase activity, glucose transport and lipid metabolism in adipocytes from normal and type-2 diabetic rats. J Mol Endocrinol 35: 27-38, 2005.

7. Pannacciulli N, Le DS, Salbe AD, Chen K, Reiman EM, Tataranni PA and Krakoff J: Postprandial glucagon-like peptide-1 (GLP-1) response is positively associated with changes in neuronal activity of brain areas implicated in satiety and food intake regulation in humans. Neuroimage 35: 511-517, 2007.

8. Ligumsky H, Wolf I, Israeli S, Haimsohn M, Ferber S, Karasik A, Kaufman B and Rubinek T: The peptide-hormone glucagon-like peptide-1 activates CAMP and inhibits growth of breast cancer cells. Breast Cancer Res Treat 132: 449-461, 2012.

9. Quoyer J, Longuet C, Broca C, Linck N, Costes S, Varin E, Bockaert J, Bertrand G and Dalle S: GLP-1 mediates antiapoptotic effect by phosphorylating Bad through a beta-arrestin 1-mediated ERK1/2 activation in pancreatic beta-cells. J Biol Chem 285: 1989-2002, 2010.

10. Elashoff M, Matveyenko AV, Gier B, Elashoff R and Butler PC: Pancreatitis, pancreatic, and thyroid cancer with glucagon-like peptide-1-based therapies. Gastroenterology 141: 150-156, 2011.

11. Bartels CL and Tsongalis GJ: MicroRNAs: Novel biomarkers for human cancer. Clin Chem 55: 623-631, 2009.

12. Liu T, Tang H, Lang Y, Liu M and Li X: MicroRNA-27a functions as an oncogene in gastric adenocarcinoma by targeting prohibitin. Cancer Lett 273: 233-242, 2009.

13. Wang L, Chen YJ, Xu K, Xu H, Shen XZ and Tu RQ: Circulating microRNAs as a fingerprint for endometrial endometrioid adenocarcinoma. PLoS One 9: e110767, 2014.

14. Samantarrai D, Dash S, Chhetri B and Mallick B: Genomic and epigenomic cross-talks in the regulatory landscape of miRNAs in breast cancer. Mol Cancer Res 11: 315-328, 2013.

15. Sun L and Fang J: Epigenetic regulation of epithelial-mesenchymal transition. Cell Mol Life Sci 73: 4493-4515, 2016.

16. Li X, Mertens-Talcott SU, Zhang S, Kim K, Ball J and Safe S: MicroRNA-27a indirectly regulates estrogen receptor \{alpha\} expression and hormone responsiveness in MCF-7 breast cancer cells. Endocrinology 151: 2462-2473, 2010.

17. Ma Y, Yu S, Zhao W, Lu Z and Chen J: miR-27a regulates the growth, colony formation and migration of pancreatic cancer cells by targeting Sprouty2. Cancer Lett 298: 150-158, 2010.

18. Mertens-Talcott SU, Chintharlapalli S, Li X and Safe S: The oncogenic microRNA-27a targets genes that regulate specificity protein transcription factors and the G2-M checkpoint in MDA-MB-231 breast cancer cells. Cancer Res 67: 11001-11011, 2007.

19. Tang W, Yu F, Yao H, Cui X, Jiao Y, Lin L, Chen J, Yin D, Song E and Liu Q: miR-27a regulates endothelial differentiation of breast cancer stem like cells. Oncogene 33: 2629-2638, 2014.

20. Hardie DG: AMP-activated protein kinase: An energy sensor that regulates all aspects of cell function. Genes Dev 25: 1895-1908, 2011.

21. Fox MM, Phoenix KN, Kopsiaftis SG and Claffey KP: AMP-activated protein kinase alpha 2 isoform suppression in primary breast cancer alters AMPK growth control and apoptotic signaling. Genes Cancer 4: 3-14, 2013.

22. Hadad SM, Baker L, Quinlan PR, Robertson KE, Bray SE, Thomson G, Kellock D, Jordan LB, Purdie CA, Hardie DG, et al: Histological evaluation of AMPK signalling in primary breast cancer. BMC Cancer 9: 307, 2009.

23. Li Z, Ni CL, Yao Z, Chen LM and Niu WY: Liraglutide enhances glucose transporter 4 translocation via regulation of AMP-activated protein kinase signaling pathways in mouse skeletal muscle cells. Metabolism 63: 1022-1030, 2014.

24. Miao XY, Gu ZY, Liu P, Hu Y, Li L, Gong YP, Shu H, Liu Y and Li CL: The human glucagon-like peptide-1 analogue liraglutide regulates pancreatic beta-cell proliferation and apoptosis via an AMPK/mTOR/P70S6K signaling pathway. Peptides 39: 71-79, 2013.

25. Ben-Shlomo S, Zvibel I, Shnell M, Shlomai A, Chepurko E, Halpern Z, Barzilai N, Oren R and Fishman S: Glucagon-like peptide-1 reduces hepatic lipogenesis via activation of AMP-activated protein kinase. J Hepatol 54: 1214-1223, 2011.

26. Livak KJ and Schmittgen TD: Analysis of relative gene expression data using real-time quantitative PCR and the 2(-Delta Delta C(T)) method. Methods 25: 402-408, 2001.

27. Zhao W, Zhang X, Liu J, Sun B, Tang H and Zhang H: miR-27a-mediated antiproliferative effects of metformin on the breast cancer cell line MCF-7. Oncol Rep 36: 3691-3699, 2016. 
28. Wei W, Zhang Q, Wang Z, Yan B, Feng Y and Li P: miR-219-5p inhibits proliferation and clonogenicity in chordoma cells and is associated with tumor recurrence. Oncol Lett 12: 4568-4576, 2016.

29. Azumi J, Tsubota T, Sakabe T and Shiota G: miR-181a induces sorafenib resistance of hepatocellular carinoma cells through downregulation of RASSF1 expression. Cancer Sci 107: 1256-1262, 2016.

30. Prado A, Andrades P and Parada F: Recent developments in the ability to predict and modify breast cancer risk. J Plast Reconstr Aesthet Surg 63: 1581-1587, 2010.

31. Schrauder MG, Fasching PA, Haberle L, Lux MP, Rauh C, Hein A, Bayer CM, Heusinger K, Hartmann A, Strehl JD, et al: Diabetes and prognosis in a breast cancer cohort. J Cancer Res Clin Oncol 137: 975-983, 2011.

32. Juanjuan L, Wen W, Zhongfen L, Chuang C, Jing C, Yiping G, Changhua W, Dehua Y and Shengrong S: Clinical pathological characteristics of breast cancer patients with secondary diabetes after systemic therapy: A retrospective multicenter study. Tumour Biol 36: 6939-6947, 2015.

33. Fidan-Yaylalı G, Dodurga Y, Seçme M and Elmas L: Antidiabetic exendin-4 activates apoptotic pathway and inhibits growth of breast cancer cells. Tumour Biol 37: 2647-2653, 2016.

34. Baggio LL and Drucker DJ: Biology of incretins: GLP-1 and GIP. Gastroenterology 132: 2131-2157, 2007.

35. Simonsen L, Pilgaard S, Orskov C, Rosenkilde MM, Hartmann B, Holst JJ and Deacon CF: Exendin-4, but not dipeptidyl peptidase IV inhibition, increases small intestinal mass in GK rats. Am J Physiol Gastrointest Liver Physiol 293: G288-G295, 2007.
36. Alves C, Batel-Marques $\mathrm{F}$ and Macedo AF: A meta-analysis of serious adverse events reported with exenatide and liraglutide: Acute pancreatitis and cancer. Diabetes Res Clin Pract 98: 271-284, 2012.

37. Li Z, Ni CL, Yao Z, Chen LM and Niu WY: Liraglutide enhances glucose transporter 4 translocation via regulation of AMP-activated protein kinase signaling pathways in mouse skeletal muscle cells. Metabolism 63: 1022-1030, 2014.

38. Ben-Shlomo S, Zvibel I, Shnell M, Shlomai A, Chepurko E, Halpern Z, Barzilai N, Oren R and Fishman S: Glucagon-like peptide-1 reduces hepatic lipogenesis via activation of AMP-activated protein kinase. J Hepatol 54: 1214-1223, 2011.

39. Tang W, Zhu J, Su S, Wu W, Liu Q, Su F and Yu F: MiR-27 as a prognostic marker for breast cancer progression and patient survival. PLoS One 7: e51702, 2012.

40. Smith U and Gale EA: Does diabetes therapy influence the risk of cancer? Diabetologia 52: 1699-1708, 2009.

41. Giovannucci E, Harlan DM, Archer MC, Bergenstal RM, Gapstur SM, Habel LA, Pollak M, Regensteiner JG and Yee D: Diabetes and cancer: A consensus report. CA Cancer J Clin 60: 207-221, 2010.

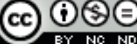

$$
\begin{aligned}
& \text { This work is licensed under a Creative Commons } \\
& \text { Attribution-NonCommercial-NoDerivatives } 4.0 \\
& \text { International (CC BY-NC-ND 4.0) License. }
\end{aligned}
$$

